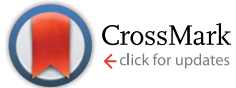

Cite this: RSC Adv., 2016, 6, 18490

Received 27th December 2015 Accepted 8th February 2016

DOI: $10.1039 / c 5 r a 27836 h$

www.rsc.org/advances

\title{
Silver nanoparticles with different size and shape: equal cytotoxicity, but different antibacterial effects $\dagger$
}

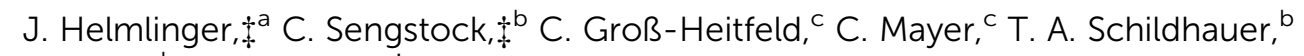 \\ M. Köller ${ }^{b}$ and M. Epple*a
}

The influence of silver nanoparticle morphology on the dissolution kinetics in ultrapure water as well as the biological effect on eukaryotic and prokaryotic cells was examined. Silver nanoparticles with different shapes but comparable size and identical surface functionalisation were prepared, i.e. spheres (diameter 40-80 and 120-180 nm; two different samples), platelets $(20-60 \mathrm{~nm})$, cubes $(140-180 \mathrm{~nm})$, and rods (diameter $80-120 \mathrm{~nm}$, length $>1000 \mathrm{~nm}$ ). All particles were purified by ultracentrifugation and colloidally stabilized with poly( $N$-vinyl pyrrolidone) (PVP). Their colloidal dispersion in ultrapure water and cell culture medium was demonstrated by dynamic light scattering. Size, shape, and colloidal stability were analysed by scanning electron microscopy, atomic force microscopy, dynamic light scattering, and differential centrifugal sedimentation. The dissolution in ultrapure water was proportional to the specific surface area of the silver nanoparticles. The averaged release rate for all particle morphologies was $30 \pm$ $13 \mathrm{ng} \mathrm{s}^{-1} \mathrm{~m}^{-2}$ in ultrapure water $\left(T=25 \pm 1{ }^{\circ} \mathrm{C} ; \mathrm{pH} 4.8\right.$; oxygen saturation 93\%), i.e. about $10-20$ times larger than the release of silver from a macroscopic silver bar $(1 \mathrm{oz})$, possibly due to the presence of surface defects in the nanoparticulate state. All particles were taken up by human mesenchymal stem cells and were cytotoxic in concentrations of $>12.5 \mu \mathrm{g} \mathrm{mL} \mathrm{L}^{-1}$, but there was no significant influence of the particle shape on the cytotoxicity towards the cells. Contrary to that, the toxicity towards bacteria increased with a higher dissolution rate, suggesting that the toxic species against bacteria are dissolved silver ions.

\section{Introduction}

Metallic nanoparticles are described as materials at the boundary between atoms and the macroscopic bulk material. Due to their small size, below $100 \mathrm{~nm}$ in at least one dimension, their specific surface area is very large and the amount of surface atoms is higher than in the bulk material. ${ }^{1}$ Specifically, silver nanoparticles are well known for their interesting properties and are widely used, e.g. in catalysis, ${ }^{2,3}$ photonics, ${ }^{4-6}$ medical applications ${ }^{7,8}$ or even energy storage and conversion. ${ }^{9}$

Concerning the biological impact of silver nanoparticles, it is well known that colloidal silver has an antimicrobial effect ${ }^{\mathbf{1 0 , 1 1}}$ that can be explained by damage to the cell membrane and

\footnotetext{
${ }^{a}$ Inorganic Chemistry and Center for Nanointegration Duisburg-Essen (CeNIDE), Universitaetsstr. 5-7, 45117 Essen, Germany. E-mail: matthias.epple@uni-due.de ${ }^{b}$ Bergmannsheil University Hospital/Surgical Research, Ruhr-University of Bochum, Buerkle-de-la-Camp-Platz 1, 44789 Bochum, Germany

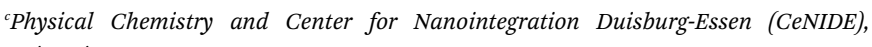
Universitaetsstr. 5-7, 45117 Essen, Germany

† Electronic supplementary information (ESI) available. See DOI: $10.1039 / \mathrm{c} 5 \mathrm{ra} 27836 \mathrm{~h}$

\$ J. Helmlinger and C. Sengstock share first authorship.
}

intracellular metabolic activity. ${ }^{\mathbf{1 2}}$ Colloidal silver is therefore an interesting "inorganic" alternative to classical antibiotics, especially for the use on medical surfaces and implants. ${ }^{13-21}$

In our previous studies on the biological effects of uniform spherical silver nanoparticles (PVP-coated, diameter $80 \mathrm{~nm}$ ) on human mesenchymal stem cells (hMSC), we have shown that cell activation occurs at elevated but non-toxic concentrations, ${ }^{22,23}$ and that adipogenic and osteogenic differentiation of hMSC were attenuated even at non-toxic concentrations. ${ }^{24}$ In addition, silver nanoparticles were taken up by hMSC and monocytes as nanoparticulate material and localized as agglomerates in the perinuclear region. ${ }^{23,25}$ Furthermore, $\mathrm{Ag}^{+}$in ionic form is much more toxic than the same molar concentration of silver in the form of nanoparticles. ${ }^{26} \mathrm{Ag}^{+}$ions are released from silver nanoparticles when oxygen is present. ${ }^{27-30}$ We have recently shown that $\mathrm{Ag}^{+}$ions which are responsible for the majority of the biological effects on various cells will precipitate as silver chloride in biological media. ${ }^{30}$

Because a strong correlation between the morphology of silver nanocrystals and their physical and biological properties (including their dissolution rate) can be predicted, the shapecontrolled synthesis of such particles has recently received growing attention. Today, a vast amount of synthetic strategies 
is available. ${ }^{31-33}$ Xia et al. and others have described the structural synthesis of nanosilver in the form of cubes, ${ }^{34-45}$ platelets, ${ }^{46-50}$ rods,${ }^{51,52}$ rings, ${ }^{53}$ and bipyramids. ${ }^{54}$ However, only little is known so far about the influence of the particle morphology on their dissolution kinetics and their toxicity in biological media.

In general, size, shape, surface charge, functionalisation, and core structure are important factors that determine the biological effects of nanoparticles, such as cellular uptake, cellular activation, as well as intercellular distribution. ${ }^{55-60}$ Sotiriou et al. have argued that smaller silver particles release silver ions faster, leading to a higher toxicity due to a higher effective silver ion concentration. They found an antibacterial effect at a silver concentration between 1 and $30 \mathrm{ppm}$, depending on the silver nanoparticle size and silver content. ${ }^{61}$

Similar results for spherical silver nanoparticles with the size of 7, 29 and $89 \mathrm{~nm}$ were observed by Martinez-Castanon et al. ${ }^{\mathbf{6 2}}$ They found that the antibacterial effect of silver nanoparticles decreased with increasing particle size. Hong et al. reported that silver nanocubes with a size of $55 \mathrm{~nm}$ had the highest antibacterial effect to $E$. coli in comparison to spheres and wires. ${ }^{63}$ However, Actis et al. reported no antibacterial effect on $S$. aureus with spherical, triangular and cubic silver nanoparticles. ${ }^{64}$ Favi et al. demonstrated that gold nanospheres were more toxic than gold nanorods for fibroblasts. ${ }^{65}$ With $E$. coli, Pal et al. found comparable results for rod-shaped, spherical, and triangular silver nanoparticles. They suggested a relation to the atomdensity of surface facets. ${ }^{66}$

Thus, the published results on different shapes of silver nanoparticles are not consistent, and the state of colloidal dispersion of the nanoparticles in cell culture media (e.g. a possible agglomeration) is not always reported in the literature. Dissolution data for different nanoparticle morphologies were not reported so far. To close this gap, we have prepared highly uniform silver nanoparticles with defined size and shape, i.e. nanospheres, nanoplatelets, nanocubes and nanorods, all with the same capping agent $\operatorname{poly}(N$-vinylpyrrolidone $)$ (PVP). All particles were purified by ultracentrifugation several times to remove free silver ions and synthesis by-products and carefully analysed by different microscopic and colloidal methods. They were colloidally stable (i.e. well dispersed) in ultrapure water as well as in cell culture medium for at least $24 \mathrm{~h}$ at $37^{\circ} \mathrm{C}$.

In the following, we present a comprehensive study about the correlation of the morphology of silver nanoparticles with their dissolution kinetics in ultrapure water and their toxicity towards eukaryotic cells and bacteria (prokaryotic cells).

\section{Experimental}

\section{General notes on the preparation of silver nanoparticles}

The reproducible synthesis of silver nanoparticles with welldefined shapes and sizes is highly sensitive towards a large number of synthetic parameters, e.g. the supplier and the purity of the applied reagents. ${ }^{33,36,39,67,68}$ Therefore, we describe our methods below in as much detail as possible.
All chemicals were used as received without further purification. All manual operations were carried out with a glass spatula to avoid contaminations with traces of iron and other metals which may influence the crystal growth and shape. ${ }^{69}$ Glass flasks and stirring bars were cleaned with aqua regia and ultrapure water $\left(18 \mathrm{M} \Omega \mathrm{cm}^{-1}\right)$ several times before they were applied.

\section{Glucose synthesis of spherical silver nanoparticles}

The synthesis of spherical silver nanoparticles by reduction of silver nitrate with glucose was carried out according to Wang et al. ${ }^{67,70}$ Briefly, $2 \mathrm{~g}$ glucose ( $\geq 99.5 \%$, Sigma-Aldrich, cat. no. G7528) and $1 \mathrm{~g}$ poly( $N$-vinylpyrrolidone) (PVP; MW $\approx 40000 \mathrm{~g}$ $\mathrm{mol}^{-1}$, Sigma-Aldrich, cat. no. 81420) were dissolved in $40 \mathrm{~mL}$ ultrapure water and stirred at $90{ }^{\circ} \mathrm{C}$ for 45 min under ambient conditions. $1 \mathrm{~mL}$ of a $2.72 \mathrm{M}$ solution of silver nitrate ( $\geq 99.9 \%$, Carl-Roth, cat. no. 7908.1) in water was quickly injected into the hot solution, and the temperature was kept for 60 min under continuous stirring. After cooling to room temperature, the particles were collected by ultracentrifugation (29 400g, $30 \mathrm{~min}$ ) and washed with acetone and ultrapure water several times.

\section{Microwave-based synthesis of spherical silver nanoparticles}

Spherical silver nanoparticles were also synthesized by a microwave-assisted polyol process. $^{71} 30 \mathrm{mg}$ silver nitrate ( $\geq 99.9 \%$, Carl-Roth) and $20 \mathrm{mg}$ PVP (MW $\approx 55000 \mathrm{~g} \mathrm{~mol}^{-1}$, Sigma-Aldrich) were completely dissolved in $5 \mathrm{~mL}$ diethylene glycol ( $\geq 99.0 \%$, Sigma-Aldrich) at room temperature. The solution assumed a light yellow colour, indicating the formation of small Ag seeds. The vial was then sealed with a PTFE cap and transferred to the microwave reactor (CEM Discover SP; 200 $\mathrm{W})$. After stirring for $1 \mathrm{~min}$ at room temperature, the solution was rapidly heated to $160{ }^{\circ} \mathrm{C}$ by the microwave at the maximum possible rate. The heating took about $120 \mathrm{~s}$. Temperature and stirring were maintained for $20 \mathrm{~min}$. During this time, the reaction was monitored with a video camera, showing a colour change from light yellow over red and green to dark brown. To stop the reaction at a defined endpoint, the solution was quickly cooled to room temperature using compressed air in the microwave within about $120 \mathrm{~s}$ and then diluted in ultrapure water. The particles were collected by ultracentrifugation $(66000 \mathrm{~g}, 30 \mathrm{~min})$ and washed with acetone and ultrapure water several times.

\section{Microwave-based synthesis of silver nanoplatelets}

Silver nanoplatelets were synthesized by microwave-assisted reduction, using a protocol described by Darmanin et al. ${ }^{\mathbf{4 9}}$ Silver nitrate ( $\geq 99.9 \%$, Carl-Roth) and ethylene glycol monoethyl ether (EEE; $\geq 99.9 \%$, Sigma-Aldrich) were heated in the presence of PVP (MW $\approx 10000 \mathrm{~g} \mathrm{~mol}^{-1}$, Sigma-Aldrich). The reaction was carried out in the microwave (CEM Discover SP, 25 to $100 \mathrm{~W}$ ). It was necessary to increase manually the microwave input power from $25 \mathrm{~W}$ up to $100 \mathrm{~W}$ at about $100{ }^{\circ} \mathrm{C}$ to achieve a reaction temperature of $140{ }^{\circ} \mathrm{C}$ after about $10 \mathrm{~min}$. All other parameters remained unchanged. After the reaction was finished, the product was cooled to room temperature and 
diluted with acetone. The particles were collected by centrifugation $(6000 \mathrm{~g}, 30 \mathrm{~min})$ and subsequently washed with acetone, ethanol, and ultrapure water before they were finally dispersed in argon-saturated ultrapure water.

\section{Synthesis of silver nanocubes}

The synthesis of silver nanocubes by the polyol process has been extensively described in the literature, ${ }^{34,35,37,38,40-44}$ but often turns out to be difficult to reproduce. ${ }^{36,39,67}$ Here, we have used a protocol developed by Xia et al. $^{34}$ and applied some modifications to optimize the particle quality. $6 \mathrm{~mL}$ ethylene glycol ( $\geq 99.8 \%$, Sigma-Aldrich) were placed in a $50 \mathrm{~mL}$ round bottom flask, sealed with a glass stopper and heated at $140{ }^{\circ} \mathrm{C}$ under constant stirring (1300 rpm, IKA RET basic hotplate). After $60 \mathrm{~min}, 30 \mu \mathrm{L}$ of $0.1 \mathrm{M} \mathrm{HCl}$ in water were added. With a two-channel syringe pump (KDS-200, KD Scientific), freshly prepared solutions of silver nitrate $\left(3 \mathrm{~mL}, 16.0 \mathrm{mg} \mathrm{mL}^{-1}\right.$, Carl Roth) and PVP $\left(3 \mathrm{~mL}, 16.2 \mathrm{mg} \mathrm{mL}{ }^{-1}, \mathrm{MW} \approx 55000 \mathrm{~g} \mathrm{~mol}^{-1}\right.$, Sigma-Aldrich) in ethylene glycol were simultaneously added at a rate of $45 \mathrm{~mL} \mathrm{~h}^{-1}$. The flask was then sealed with a glass stopper. Heating and stirring were continued. Due to the poor solubility of PVP in ethylene glycol, the initial solution was placed into an ultrasonic bath before injection until all visible solid PVP had been dissolved. After $20 \mathrm{~h}$, the reaction was stopped by externally cooling the flask with water to room temperature and adding $10 \mathrm{~mL}$ of analytical grade acetone. This lead to a yellow/ochre colloidal dispersion. The particles were collected by ultracentrifugation (29 400g, $30 \mathrm{~min}$ ). To remove silver nanowires, which typically occur as a by-product, filtration was performed with $0.45 \mu \mathrm{m}$ cellulose syringe filters. The particles were isolated by ultracentrifugation $(29400 \mathrm{~g}, 30$ min) and washed with acetone and ultrapure water several times. The final dispersion was stored in argon-saturated ultrapure water.

\section{Synthesis of silver nanowires}

Silver nanowires were obtained by a modified polyol process where silver chloride nanocubes were generated in situ by the reaction of silver nitrate with sodium chloride as described by Buhro et al. $^{52}$ The AgCl seeds served as a heterogeneous nuclei for the growth of silver nanowires. The reaction was performed in ethylene glycol ( $\geq 99.8 \%$, Sigma-Aldrich) in the presence of PVP (MW $\approx 55000 \mathrm{~g} \mathrm{~mol}{ }^{-1}$, Sigma-Aldrich), with a lowconcentration addition of sodium chloride $(\geq 99.9 \%$, VWR Chemicals) and silver nitrate ( $\geq 99.9 \%$, Carl-Roth), exactly following the protocol described in the literature. ${ }^{52}$ After the seeding was completed, silver nanowires were produced by adding $10 \mathrm{~mL}$ of a $0.12 \mathrm{M}$ silver nitrate solution in ethylene glycol with a syringe pump (KDS-200, KD Scientific). The particles were collected by centrifugation $(666 g, 30 \mathrm{~min})$ and redispersed in ultrapure water with ultrasonication. The particles were washed with aqueous ammonia ( $2 \mathrm{~mL} 30 \%$ aqueous $\mathrm{NH}_{3}$ given to $5 \mathrm{~mL}$ particle dispersion) to remove excess silver chloride, centrifuged again under the same conditions and rinsed with ultrapure water several times.

\section{Storage and analytical methods}

After purification, all particles were stored in argon-saturated, ultrapure water and kept in the dark to avoid dissolution or chemical aging. All particles were colloidally stable for at least 6 months under these conditions. To determine the size and shape of the metallic particle core, $10 \mu \mathrm{L}$ of a dispersion was dripped on a silicon wafer, dried at room temperature in air, and analysed by scanning electron microscopy (SEM) with a FEI Quanta 400 ESEM instrument in high vacuum without sputtering. Atomic force microscopy (AFM) was performed with a NanoWizard from JPK (Berlin) in the intermittent contact mode. Hydrodynamic particle diameter, zeta potential and polydispersity index (PDI) were determined by dynamic light scattering (DLS) using a Malvern Zetasizer Nano ZS. The particle size distribution and colloidal stability in cell culture medium (RPMI/FBS) after $24 \mathrm{~h}$ at $37{ }^{\circ} \mathrm{C}$ were also measured by DLS. Furthermore, differential centrifugal sedimentation was performed for all particles with a CPS Instruments Disc Centrifuge DC 24000 at $25{ }^{\circ} \mathrm{C}$. Two sucrose solutions ( $8 \mathrm{wt} \%$ and $24 \mathrm{wt} \%$ ) were used to provide a density gradient with dodecane as stabilizing agent. The calibration standard was a dispersion of poly(vinyl chloride) (PVC) particles in water. The silver concentration in the particle dispersions was analysed by atomic absorption spectroscopy (Thermo Electron Corporation, M-Series, detection limit $1 \mu \mathrm{g} \mathrm{L}^{-1}$ ) after dissolving $500 \mu \mathrm{L}$ of each sample in $4.5 \mathrm{~mL}$ concentrated nitric acid and $5 \mathrm{~mL}$ ultrapure water.

\section{Dissolution in ultrapure water}

The dissolution kinetics were examined by dialysis in triplicate for each kind of nanoparticles. After all silver ions were removed by ultracentrifugation and redispersion in water as described above, $4 \mathrm{~mL}$ silver nanoparticle dispersion $\left(0.1 \mathrm{mg} \mathrm{mL}^{-1} \mathrm{Ag}\right)$ were transferred in dialysis bags (Spectra/Por Biotech; cellulose ester; MWCO 100 000) and immersed in $396 \mathrm{~mL}$ ultrapure water. The dialysis bags were rinsed with ultrapure water several times before use. Temperature, $\mathrm{pH}$-value and oxygen saturation of the medium were recorded during the experiment. The dialysis was carried out under slow stirring for $696 \mathrm{~h}$ (29 days) in sealed polypropylene-tubes. The dissolved amount of $\mathrm{Ag}^{+}$ions was determined by atomic absorption spectroscopy on aliquots of $9 \mathrm{~mL}$ taken after selected times. The aliquot volume was not replenished.

The silver bar was immersed in $500 \mathrm{~mL}$ of ultrapure water without stirring to avoid mechanical abrasion of the metal. After $700 \mathrm{~h}$, the solution was gently mixed and a sample was taken and analysed for the silver content.

\section{Cell culture experiments}

Human mesenchymal stem cells (hMSC, $3^{\text {rd }}$ to $7^{\text {th }}$ passage, Lonza, Walkersville Inc., MD, USA) were cultured in RPMI1640 medium (Life Technologies, Darmstadt, Germany) containing $10 \%$ fetal calf serum (FCS, Life Technologies) and L-glutamine (0.3 $\mathrm{g} \mathrm{L}^{-1}$, Life Technologies) using $75 \mathrm{~cm}^{2}$ flasks (Falcon, Becton Dickinson GmbH, Heidelberg, Germany). Cells were 
maintained at $37{ }^{\circ} \mathrm{C}$ in a humidified atmosphere of $5 \% \mathrm{CO}_{2}$. Depending on the cell proliferation, the cells were subcultivated every 7-14 days. Adherent cells were washed with phosphate-buffered saline solution (PBS, Life Technologies) and detached from the culture flasks by addition of $0.2 \mathrm{~mL}$ $\mathrm{cm}^{-2} \quad 0.25 \%$ trypsin/0.05\% ethylendiamine tetraacetic acid (EDTA, Sigma-Aldrich, Taufkirchen, Germany) for $5 \mathrm{~min}$ at 37 ${ }^{\circ} \mathrm{C}$. Subsequently, the hMSC were collected and washed twice with RPMI1640/10\% FCS. To determine the effect of silver nanoparticles on cell viability and morphology, hMSC were incubated with different concentrations of silver nanoparticles under cell culture conditions. After $24 \mathrm{~h}$ of incubation, the treated cells were stained with the cell-permeant dye calceinacetoxymethylester (calcein-AM, Calbiochem, Schwalbach, Germany). For this, the nanoparticle-treated cells were washed twice with RPMI and incubated with calcein-AM (1 mM) at $37^{\circ} \mathrm{C}$ for $30 \mathrm{~min}$ under cell culture conditions. Subsequently, the adherent cells were washed with RPMI and analysed by fluorescence microscopy (Olympus MVX10, Olympus, Hamburg, Germany). Fluorescence microphotographs were taken (CellP, Olympus), and digitally processed using AdobePhotoshop ${ }^{\circledR} 7.0$.

Confocal laser scanning microscopy (CLSM) was used to detect intracellular silver nanoparticles in hMSC after incubation. Therefore, hMSC were subconfluently grown on 2-well LabTek $^{\mathrm{TM}}$ glass chamber slides (Thermo Fisher Scientific, Langenselbold, Germany), and subsequently washed and exposed to $12.5 \mu \mathrm{g} \mathrm{mL}{ }^{-1}$ silver nanoparticles for $24 \mathrm{~h}$ under cell culture conditions. After this incubation, the cells were incubated with $162 \mu \mathrm{M}$ Hoechst33342 in pure RPMI1640 for $5 \mathrm{~min}$ at $37^{\circ} \mathrm{C}$ for labelling of the nucleus. After three rinses in RPMI1640, the cells were put on glass chamber slides. Images were taken using a $40 \times$ oil immersion objective in CLSM (LSM700; Zeiss) and Zeiss 2010 software.

\section{Bacterial culture experiments}

Antimicrobial tests were performed with Staphylococcus aureus (DSMZ 1104) obtained from Life Technologies GmbH (Karlsruhe, Germany). Bacterial concentrations of overnight cultures were measured using a Densichek $₫$ (bioMérieux, Lyon, France) turbidity photometer. The calculation of bacterial counts was based on turbidity standard solutions (McFarland scale).

The antimicrobial effect of silver nanoparticles with different morphologies was tested using a standard method that determines the minimum bactericidal concentration (MBC). The MBC was determined in RPMI 1640 containing 10\% (v/v) fetal calf serum and L-glutamine and defined as the lowest silver concentration that completely prevented colony forming units (CFU) on the agar plate. Working silver stock solutions with different concentrations $(50 \mu \mathrm{L})$ were added to different bacteria concentrations $\left(10^{2}\right.$ to $\left.10^{5} \mathrm{~mL}^{-1}\right)$ for inoculation. Cells were incubated in a cell culture incubator (RPMI/10\% FCS) at $37{ }^{\circ} \mathrm{C}$ overnight. The minimum bactericidal concentration (MBC) was subsequently determined by plating $100 \mu \mathrm{L}$ aliquots of the samples on blood agar platelets.

\section{Statistical analysis}

Data are expressed as mean \pm SD of four independent experiments. Analysis of the data distribution was performed using the Student's $t$-test to analyze the significance of differences between the treated group and the control group (without silver exposure). $p$ values of less than 0.05 were considered as statistically significant.

\section{Results and discussion}

The reproducible synthesis of silver nanoparticles with defined morphologies is very challenging due to the high number of reaction parameters that must be monitored and controlled. ${ }^{36,39}$ Furthermore, if the particles shall be applied in biological systems as antibacterial agent, they must satisfy specific requirements. Size and shape should be analysed by different analytical methods, the particles must be separated from synthesis by-products that might interfere with the biological system, the colloidal stability in cell culture medium must be given at physiological temperatures over the period of the experiments, and the concentration must be high enough to cause a significant biological effect.

Based on these requirements, we have chosen different syntheses from the literature and modified them if necessary. We have also taken into account that all particles are stabilized with the same ligand (PVP) to minimize a possible influence of

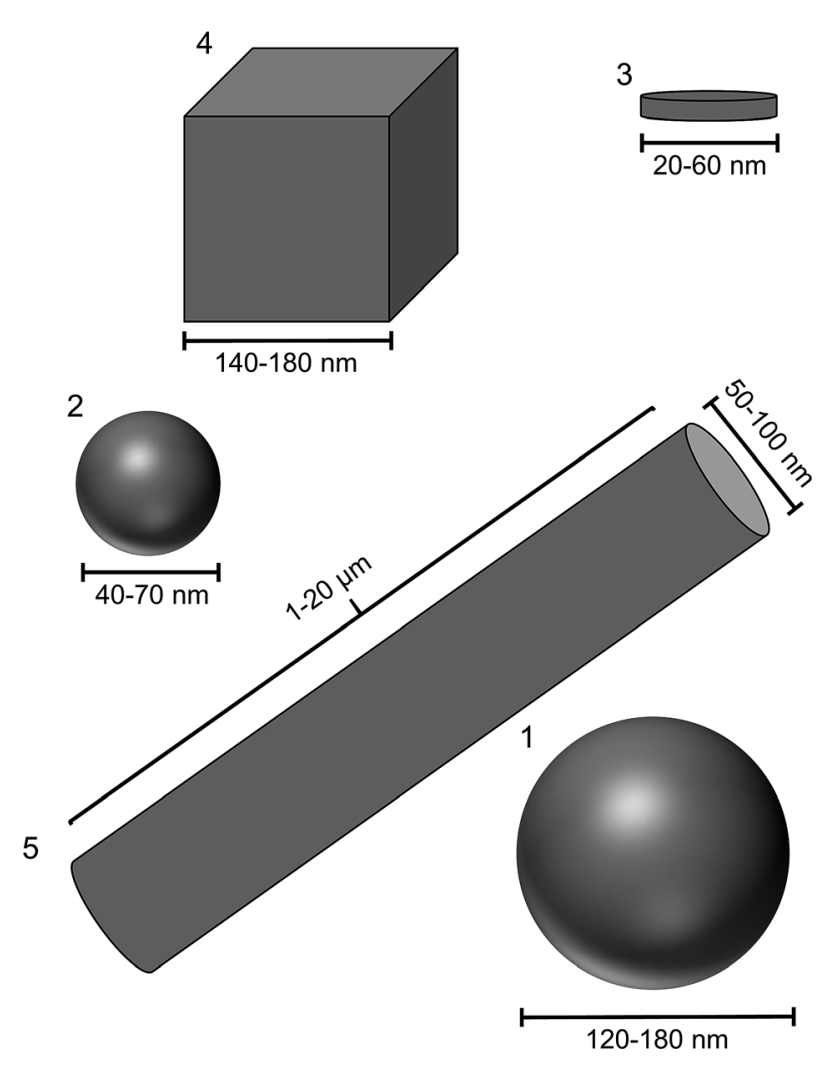

Fig. 1 Size and shape of the different silver nanoparticles. (1) Spheres from glucose synthesis; (2) spheres from microwave synthesis; (3): platelets; (4): cubes; (5): rods (longer than shown here). 
the organic shell on the particle properties. Of course, it is impossible to prepare particles with exactly the same size, but with different shape. We have prepared two different types of spherical particles, one from a glucose synthesis ${ }^{72}$ and one from a microwave synthesis. ${ }^{71}$ The spherical particles from the microwave synthesis are about two times larger than the particles from the glucose synthesis. Fig. 1 schematically shows the size and morphology of the different particles.

All particles were highly uniform in size and shape as shown by scanning electron microscopy (Fig. 2). The dimensions of the metallic particle cores are summarized in Table 1. The base area of the platelets was either triangular or circular as described in the literature. ${ }^{\mathbf{4 9}}$ The cubes had very sharp edges. A very small amount of prisms and pentagonal decahedra occurred as by-products during the synthesis. The rods were highly anisotropic with diameters in the range of 50-100 $\mathrm{nm}$ and lengths up to $20 \mu \mathrm{m}$. Although it must be acknowledged that it is impossible to prepare silver nanoparticles with $100 \%$ identical size and shape, the differences among the samples 1 to 5 (Fig. 1) are clearly larger than the variation within each sample.

Differential centrifugal sedimentation was performed with all particles. This method relies on the sedimentation of nanoparticles in a density gradient under centrifugal force. We were not able to acquire meaningful data for the silver nanorods because they were sedimenting too fast even at the lowest possible disc speed. Note that differential centrifugal sedimentation tends to underestimate the particle diameters because the density of the pure metal is used in the calculation, while the effective density is lower due to the organic ligand shell. On the other hand, the polymer- and hydration layers are contributing to the particle diameters. Furthermore, the particles are assumed as spherical, leading to deviations for the platelets and cubes. Nevertheless, the results (Table 1) reasonably agree with the electron microscopic data.

The size distribution in solution and the colloidal stability were determined by dynamic light scattering (DLS), and the zeta potential in ultrapure water was measured. The results are given in Table 1 and Fig. S1 (ESI†). All particles were colloidally stable in ultrapure water as well as in cell culture medium (RPMI/FBS) over the observation period of $24 \mathrm{~h}$ at $37{ }^{\circ} \mathrm{C}$. In cell culture medium, the particle diameters slightly increased, probably due to the formation of a protein corona. ${ }^{45}$ Similar to differential centrifugal sedimentation, the particles are assumed as spherical, leading to deviations for silver nanorods. All other diameters agreed well with the results obtained by SEM. The zeta potential was negative in all cases, i.e. the particles were electrosterically stabilized.

As it is difficult to determine the height of silver nanoplatelets by scanning electron microscopy, we have performed atomic force microscopy on platelets and spheres from the glucose synthesis. Fig. 3 shows a typical line scan analysis as well as a magnified image for both kinds of particles. We manually selected ten particles from each sample and determined their average width and height. The mean value for the thickness of the platelets was $16 \mathrm{~nm}$ and agreed to the value of 10-15 $\mathrm{nm}$ as reported by Darmanin et al. ${ }^{49} \mathrm{We}$ also calculated the aspect ratio for both kind of particles. The ratio was $5: 1$ for the platelets and $3: 1$ for the spheres.

The influence of the particle morphology on the dissolution kinetics of silver nanoparticles was examined by dialysis. It was shown that silver nanoparticles dissolve in water under the formation of $\mathrm{Ag}^{+}$ions when oxygen is present. ${ }^{27,29,30,73-78}$ The released $\mathrm{Ag}^{+}$ions are small enough to pass a cellulose-ester membrane and can be detected by AAS, while the nanoparticles are retained inside the dialysis bag. ${ }^{27,30}$

Fig. 4 shows the dissolved amount of $\mathrm{Ag}^{+}$from nanoparticles as function of time. We chose ultrapure water as the dissolution medium $\left(T=25 \pm 1{ }^{\circ} \mathrm{C} ; \mathrm{pH}=4.8\right.$; oxygen saturation $\left.=93 \%\right)$, which is of course a simplified model system. Diendorf et al. have shown that in biological media, complexation and precipitation by biomolecules and salts must be taken into account because they significantly influence the dissolution kinetics. ${ }^{30}$

It is obvious from Fig. 4 that the particle morphology has a significant effect on the release of $\mathrm{Ag}^{+}$ions. After 696 hours (29 days), $68 \pm 1 \mathrm{wt} \% \mathrm{Ag}$ of the platelets were dissolved as $\mathrm{Ag}^{+}$, followed by spheres from the glucose synthesis ( $54 \pm 3 \mathrm{wt} \% \mathrm{Ag})$, spheres from the microwave synthesis ( $42 \pm 8 \mathrm{wt} \% \mathrm{Ag})$, rods (37 $\pm 1 \mathrm{wt} \% \mathrm{Ag})$ and finally cubes (30 $\pm 1 \mathrm{wt} \% \mathrm{Ag})$. As expected, the amount of dissolved silver from the glucose particles matched the value of $\sim 53 \% \mathrm{wt} \% \mathrm{Ag}$ which was obtained by Kittler et al. for the same particles under the same conditions. ${ }^{27}$

We have estimated the specific surface area for all particles by simplified geometric calculations and correlated the results with the experimentally determined dissolution kinetics. For this, we have calculated the volume and surface for the particles, assuming ideal spheres and cubes. Platelets and rods are assumed as cylindrical with a circular base. For particle radii, heights and edge lengths we have chosen reasonable average values for the metallic particle core from experimentally obtained scanning electron micrographs (Table 2).

The trend of the dissolution rate was as follows (Table 2):

platelets $>$ spheres glucose synthesis $>$ spheres microwave synthesis $\approx$ rods $>$ cubes

The specific surface area follows the same trend. When compared to the experimentally determined dissolution rates (Fig. 4), these results indicate a strong correlation between the specific surface area and the dissolution kinetics for silver nanoparticles. Particles with a higher specific surface area dissolve faster than those with a smaller specific surface area, leading to the assumption that the oxidation of $\mathrm{Ag}$ to $\mathrm{Ag}^{+}$on the particle surface is the rate-determining step of the dissolution.

If the silver release rate is normalized to the particle surface, values between 12 and $44 \mathrm{ng} \mathrm{s}^{-1} \mathrm{~m}^{-2}$ are obtained. On average, the silver dissolution rate is $30 \pm 13 \mathrm{ng} \mathrm{s}^{-1} \mathrm{~m}^{-2}$. Here, differences in the silver release rate from different crystallographic faces are neglected. Remarkably, the dissolution rate of a silver bar ( $1 \mathrm{oz}$ ) immersed in pure water for $696 \mathrm{~h}$ was about one order of magnitude smaller $\left(2 \mathrm{ng} \mathrm{s}{ }^{-1} \mathrm{~m}^{-2}\right.$ compared to the nanoparticles). This can tentatively ascribed to defects 

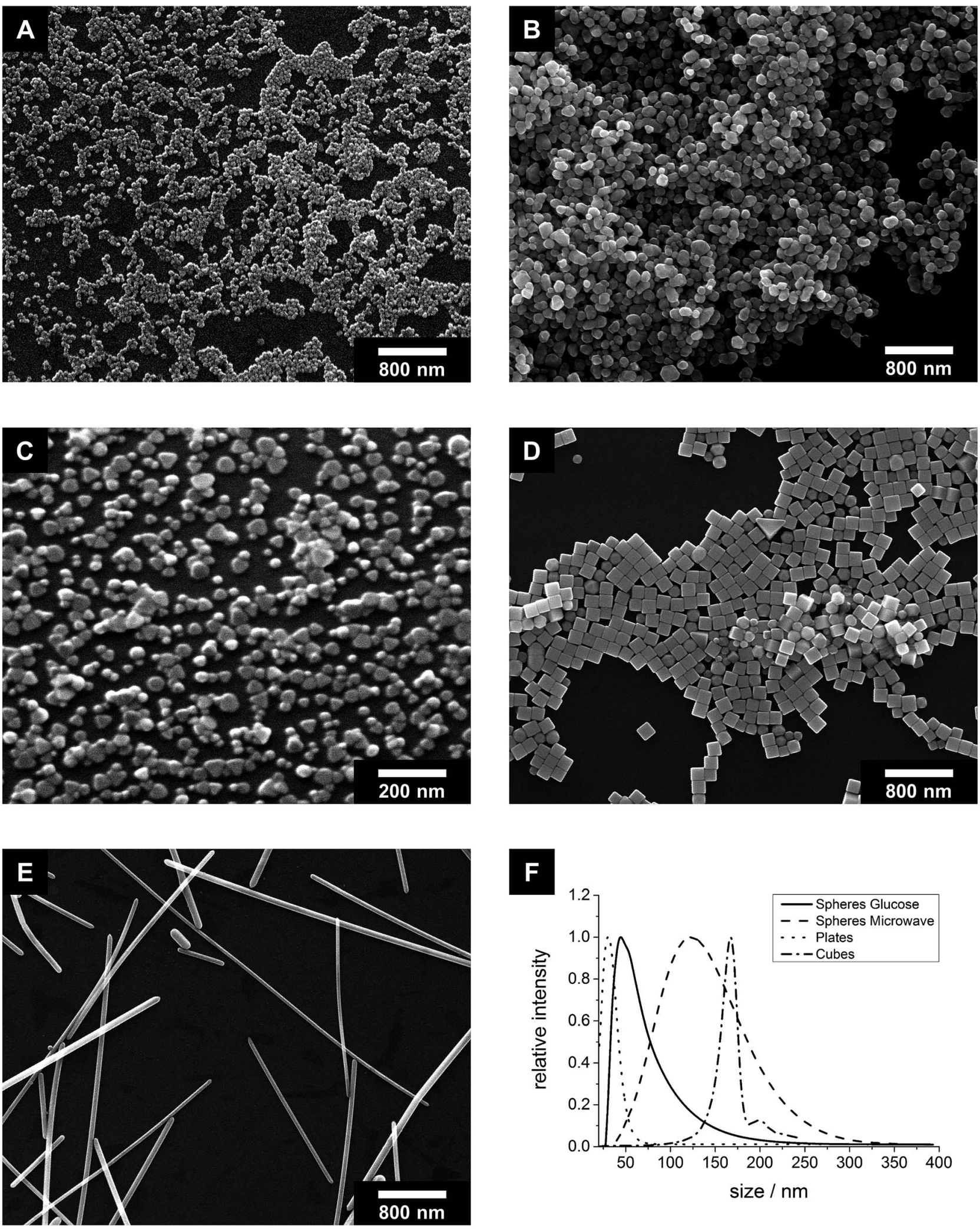

Fig. 2 Representative SEM images of (A) silver nanospheres from glucose synthesis, (B) silver nanospheres from microwave synthesis, (C) silver nanoplatelets, (D) silver nanocubes, and (E) silver nanorods. (F) Shows the size distribution of all particles except silver nanorods in ultrapure water as obtained by differential centrifugal sedimentation. 
Table 1 Size and zeta potential of silver nanoparticles as measured by different analytical methods

\begin{tabular}{|c|c|c|c|c|c|}
\hline & Spheres glucose synthesis & $\begin{array}{l}\text { Spheres microwave } \\
\text { synthesis }\end{array}$ & Platelets & Cubes & Rods \\
\hline SEM & $40-70 \mathrm{~nm}$ & $120-180 \mathrm{~nm}$ & $20-60 \mathrm{~nm}$ & $140-180 \mathrm{~nm}$ & $\begin{array}{l}\text { Diameter: } 50-100 \mathrm{~nm} \text {, } \\
\text { length: } 1000-20000 \mathrm{~nm}\end{array}$ \\
\hline DCS & $45 \mathrm{~nm}$ & $123 \mathrm{~nm}$ & $30 \mathrm{~nm}$ & $167 \mathrm{~nm}$ & - \\
\hline DLS & $108 \mathrm{~nm}$ & $128 \mathrm{~nm}$ & $48 \mathrm{~nm}$ & $211 \mathrm{~nm}$ & $558 \mathrm{~nm}$ \\
\hline AFM & $\begin{array}{l}\text { Diameter: } 145 \mathrm{~nm} \text {, } \\
\text { height: } 48 \mathrm{~nm}\end{array}$ & - & $\begin{array}{l}\text { Diameter: } 80 \mathrm{~nm} \text {, } \\
\text { height: } 16 \mathrm{~nm}\end{array}$ & - & - \\
\hline
\end{tabular}

in the surface of nanoparticles compared to a macroscopic metallic alloy.

The biological effect of the different silver nanoparticle shapes on prokaryotic and eukaryotic cells was analysed. To ensure comparable conditions, we have used RPMI 1640 with $10 \%(\mathrm{v} / \mathrm{v})$ FCS as culture medium in both cases. This medium is typically used for the cultivation of mammalian cells. It represents a good approximation of in vivo conditions where the antibacterial action is desired. In addition, we have already shown that PVP-stabilized silver nanoparticles remain well dispersed in this medium. ${ }^{79}$
Human mesenchymal stem cells (hMSC) as typical tissuelike cells were cultured in the presence of $12.5 \mu \mathrm{g} \mathrm{mL} \mathrm{m}^{-1}$ silver nanoparticles at $37^{\circ} \mathrm{C}$ for $24 \mathrm{~h}$ under cell culture conditions. The uptake of the silver nanoparticles was analysed by CLSM. Nanoplatelets were visible in the perinuclear region as agglomerates (white arrow) close to the cell nucleus but not within the cell nucleus (Fig. 5A). The cell nucleus was labelled by using Hoechst33342 (blue fluorescence). Similar results were observed for the nanoparticles of other shapes (see ESI Fig. S2 $†$ ). In previous studies we have shown by combined FIB/SEM and EDX that hMSC are able to internalize spherical silver nanoparticles. ${ }^{25}$
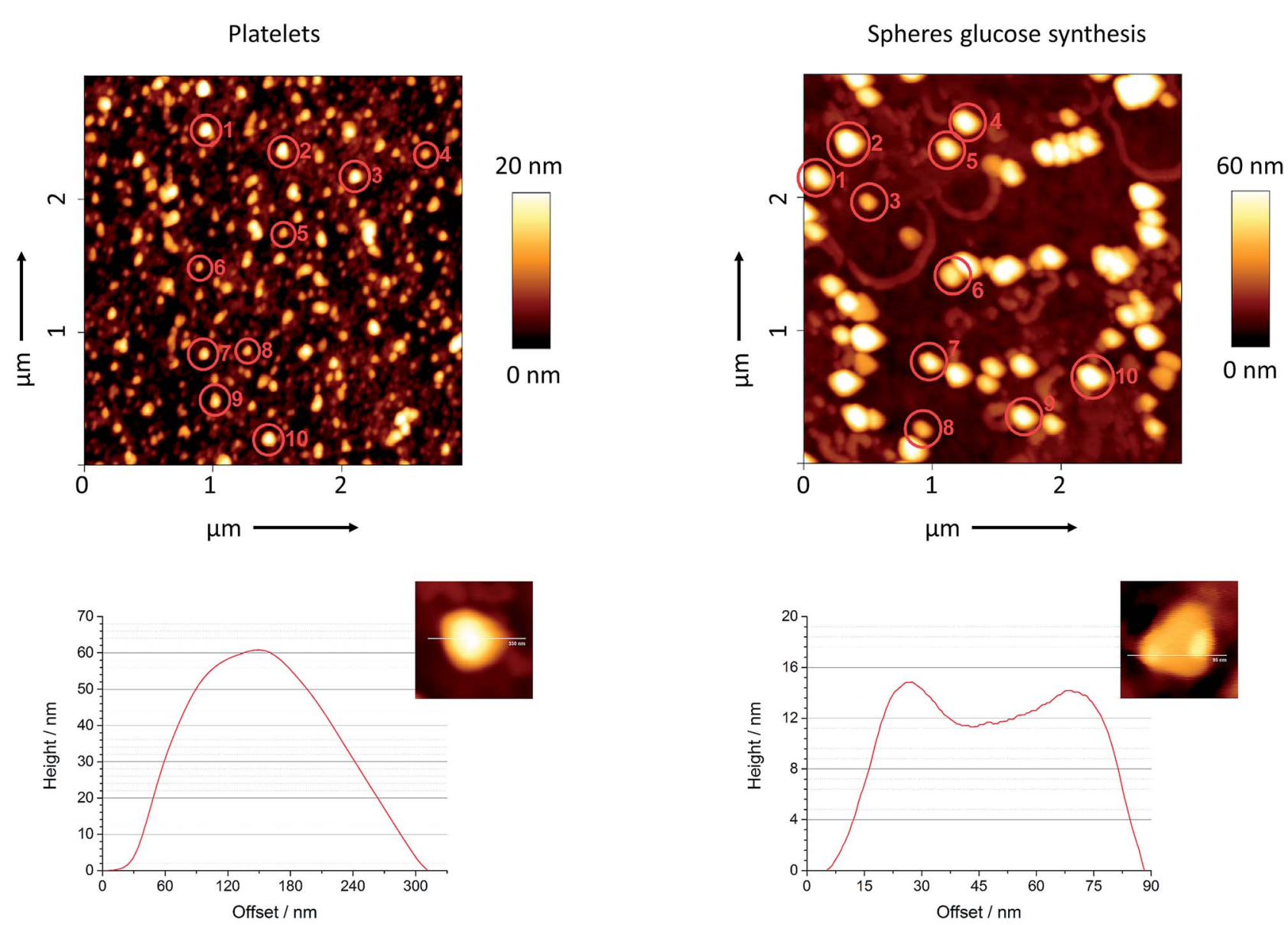

Fig. 3 Topology of silver nanoplatelets (left) and silver nanospheres from glucose synthesis (right). Ten individual particles were selected from each sample and their diameter and height were manually measured by atomic force microscopy. 


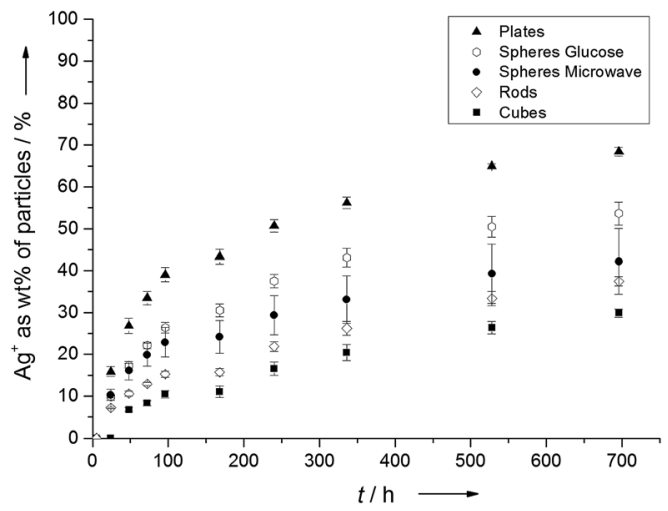

Fig. 4 Experimentally determined dissolution kinetics of silver nanoparticles with different morphologies.

The uptake of silver was additionally analysed by flow cytometry using the side-scatter signal (Fig. 5B). Flow cytometry was also used by Stringer et al. and Suzuki et al. after the uptake of nanoparticles into cells. ${ }^{\mathbf{8 0 , 8 1}}$ The scattering intensity is increased by the increased light scattering from the dense ingested particles. In our study, the size of the internalized nano- or agglomerated particles (Table 1) clearly correlated with the side-scatter intensity signal (SSC-signal; Fig. 5B). The SSC-signal is correlated with the intensity of the light scattered by a particle, and this is increasing with particle or agglomerate size. Therefore, the increased SSC-signal of the nanoparticle-treated cells reflects the size of the internalized particles/agglomerates rather than an uptake rate or the particle number.

The viability of the nanoparticle-treated cells was analysed by calcein-AM staining and fluorescence microscopy. After incubation of hMSC with silver nanoparticles an increasing, dosedependent cytotoxic effect occurred (Fig. 6). There was a statistically significant effect on cell viability in the presence of $>\mathbf{1 2 . 5}$ $\mu \mathrm{g} \mathrm{mL}^{-1}$ silver nanoparticles with different morphologies compared to cells treated without silver $\left(0 \mu \mathrm{g} \mathrm{mL}^{-1}\right)$. For spherical silver nanoparticles, similar results were reported by our group. ${ }^{\mathbf{2 4 2 6}}$ It is remarkable that there was no silver nanoparticle shape-dependent effect on hMSC under these cell culture conditions (Fig. 6).

In addition to the biological effect of silver nanoparticles to mammalian cells, the antimicrobial effect of silver nanoparticles towards $S$. aureus was studied by the determination of the minimal bactericidal concentration (MBC). As represented in Fig. 7, silver nanoparticles $\left(25 \mu \mathrm{g} \mathrm{mL}{ }^{-1}\right)$ showed an antimicrobial effect on $S$. aureus and in addition an increase in the MBC when the bacterial number was increased (see different quadrants in Fig. 7). Comparable results have been described in the literature for $\beta$-lactam antibiotics. ${ }^{82}$ This effect is well known as the inoculum effect. ${ }^{26,83}$ Interestingly, in addition to this effect, a particle shape-dependent effect on antibacterial activity was observed.

Silver nanoplatelets showed the highest antibacterial effect, followed by spheres from the glucose synthesis, spheres from the microwave synthesis, rods, and finally cubes (Table 3). This toxic effect towards $S$. aureus correlates to the silver ion release (Fig. 4).

We have shown that particles with a higher specific surface area such as platelets dissolve faster than particles with a smaller specific surface area such as cubes. This increased silver ion release for particles with higher specific surface area was obviously the reason for the observed increased antimicrobial effect. However, this effect was observed only for bacteria. The antibacterial effect was related to the shape of the silver nanoparticles at same total silver concentration, but this was not observed for eukaryotic cells.

We therefore suggest that the antibacterial mechanism is only related to the silver ion release because bacteria are probably unable to ingest the used silver nanoparticles in contrast to hMSC. $^{25}$ Wang et al. demonstrated that $16 \mathrm{~nm}$ gold nanospheres adhered well to the surface of Salmonella typhimurium, but were unable to get into the bacteria. ${ }^{84}$ In

Table 2 Estimated specific surface area as well as used mean values for particle radii, heights and edge lengths for silver nanoparticles with different shapes, approximated using ideal geometries and average edge lengths. The silver concentration was $100 \mu \mathrm{g} \mathrm{mL} \mathrm{m}^{-1}$ in all cases, except for the silver bar

\begin{tabular}{|c|c|c|c|c|c|c|}
\hline & $\begin{array}{l}\text { Spheres glucose } \\
\text { synthesis }\end{array}$ & $\begin{array}{l}\text { Spheres microwave } \\
\text { synthesis }\end{array}$ & Platelets & Cubes & Rods & Silver bar $(1 \mathrm{oz})$ \\
\hline Radius/nm & 30 & 75 & 20 & - & 50 & - \\
\hline Edge length/nm & - & - & - & 160 & - & $\begin{array}{l}5 \times 10^{7}(50 \mathrm{~mm}) \\
2.8 \times 10^{7}(28 \mathrm{~mm})\end{array}$ \\
\hline Volume per particle $/ \mathrm{nm}^{3}$ & $1.13 \times 10^{5}$ & $1.77 \times 10^{6}$ & $1.88 \times 10^{4}$ & $4.10 \times 10^{6}$ & $3.14 \times 10^{7}$ & $2.98 \times 10^{21}$ \\
\hline Particle concentration $/ \mathrm{mL}^{-1}$ & $8.43 \times 10^{10}$ & $5.39 \times 10^{9}$ & $5.06 \times 10^{11}$ & $2.33 \times 10^{9}$ & $3.03 \times 10^{8}$ & - \\
\hline Total particle surface $/ \mathrm{m}^{2} \mathrm{~mL}^{-1}$ & $9.54 \times 10^{-4}$ & $3.81 \times 10^{-4}$ & $2.22 \times 10^{-3}$ & $3.58 \times 10^{-4}$ & $3.86 \times 10^{-4}$ & - \\
\hline $\begin{array}{l}\text { Dissolution of Ag per time/ } \mu \mathrm{g} \mathrm{mL}^{-1} \mathrm{~s}^{-1} \\
\text { (average after } 696 \mathrm{~h} \text { ) }\end{array}$ & $2.14 \times 10^{-5}$ & $1.68 \times 10^{-5}$ & $2.73 \times 10^{-5}$ & $1.19 \times 10^{-5}$ & $1.49 \times 10^{-5}$ & $6.24 \times 10^{-6}$ \\
\hline Dissolution rate of $\mathrm{Ag}$ per time and & 22 & 44 & 12 & 33 & 39 & 2 \\
\hline
\end{tabular}



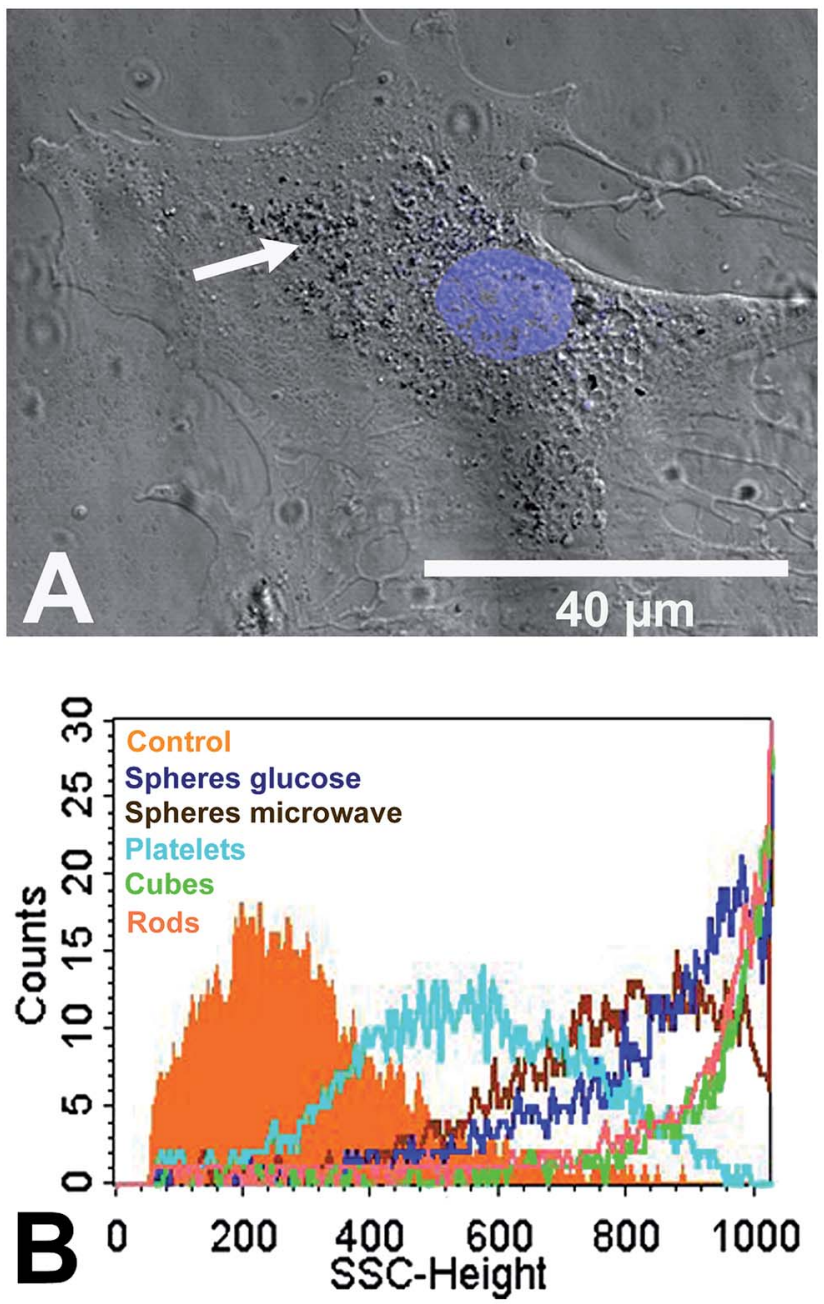

Fig. 5 Intracellular occurrence of silver nanoparticles agglomerates analysed by phase-contrast microscopy and flow cytometric side scatter analysis. (A) Representative phase-contrast micrograph of hMSC treated with $12.5 \mu \mathrm{g} \mathrm{mL}-1$ silver nanoplatelets at $37^{\circ} \mathrm{C}$ for $24 \mathrm{~h}$ under cell culture conditions. The white arrow denotes perinuclear accumulation of nanoparticles. The blue fluorescence of Hoechst33342 was used to stain the cell nucleus. (B) A representative flow cytometric histogram of the side scatter intensity signal for hMSC treated without (control) or with different silver nanoparticles morphologies.

another study, Butler et al. demonstrated by transmission electron microscopy that silver nanoparticles with a size of 10 $\mathrm{nm}$ or larger were not internalized into S. typhimurium or $E$. coli. ${ }^{85}$ In general, there are only few studies in the literature on the uptake of nanoparticles in bacteria. Kumar et al. have shown by flow cytometry that nanoparticles of zinc oxide $(\mathrm{ZnO})$ and titanium dioxide $\left(\mathrm{TiO}_{2}\right)$ were taken up by $E$. coli. ${ }^{86}$ However, the authors did not distinguish between internalized and adherent nanoparticles. Butler $e$ t al. have shown by transmission electron microscopy and energy dispersive $\mathrm{X}$ ray spectroscopy that $\mathrm{TiO}_{2}$ nanoparticles were associated with bacteria (surrounding them almost completely), but that they were not internalized. ${ }^{87}$ In contrast to the interaction with bacteria, we have shown earlier that hMSC are able to

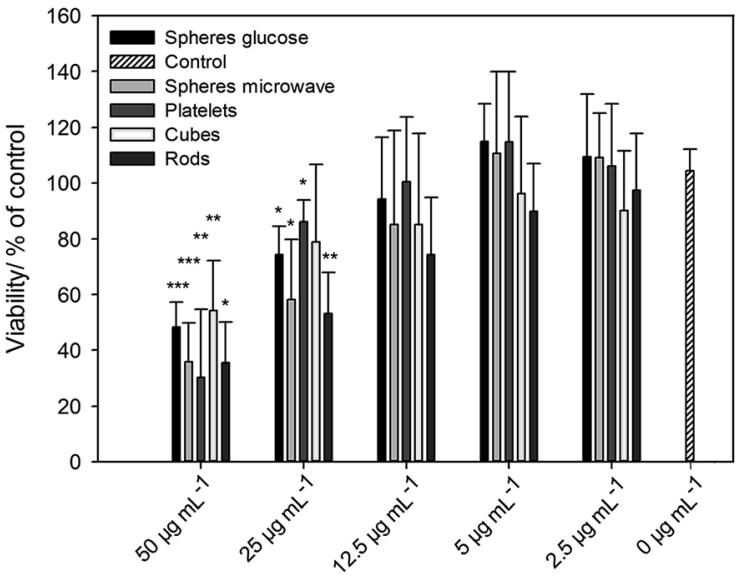

Fig. 6 Effects of silver nanoparticles with different morphologies on the viability of cells as analysed by calcein-AM staining and digital image processing (phase analysis). The hMSC were treated with different concentrations of silver nanoparticles ( $\mu \mathrm{g} \mathrm{mL}^{-1}$ ) for $24 \mathrm{~h}$ under cell culture conditions. The quantitative data are expressed as the mean $\pm S D$ of four independent experiments, given as a percentage of the control (cells cultured without silver, $0 \mu \mathrm{g} \mathrm{mL}^{-1}$ ). An asterisk (*) indicates significant differences in comparison to the control without silver $\left({ }^{*} p<0.05, * * p<0.005, * * * p<0.001\right)$.
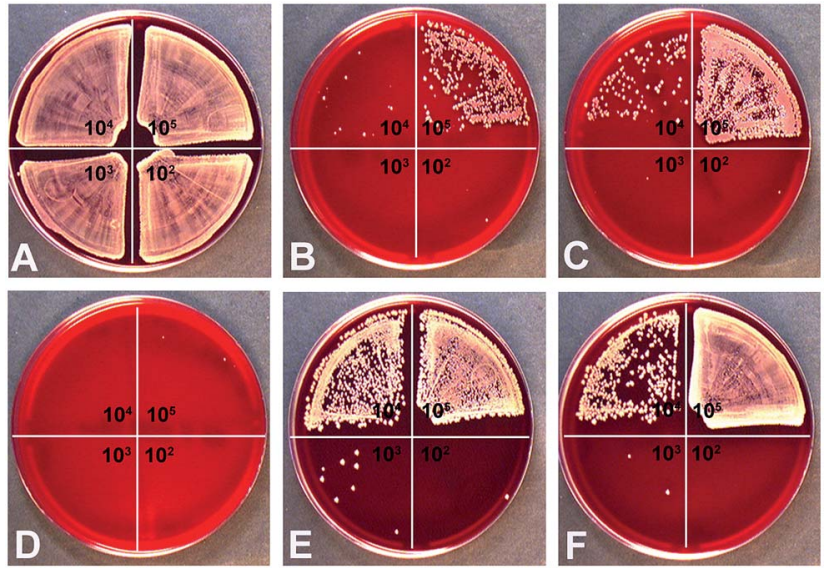

Fig. 7 Effects of silver nanoparticles with different shape on the viability of $S$. aureus. Representative images of $S$. aureus colonies on blood agar platelets. $S$. aureus with different bacteria concentrations (top right quadrant $1 \times 10^{5}$; lower right quadrant $1 \times 10^{2}$; top left quadrant $1 \times 10^{4}$; lower left quadrant $1 \times 10^{3}$ ) were treated without $(A)$ or with $25 \mu \mathrm{g} \mathrm{mL}^{-1}$ silver nanoparticles with different particles shapes ((B): sphere from glucose synthesis; (C): spheres from microwave synthesis; (D): platelets; $(E)$ : cubes and (F): rods) under cell culture conditions. After $24 \mathrm{~h}$ the bacteria were plated $(100 \mu \mathrm{L})$ on blood agar platelets and incubated for another $24 \mathrm{~h}$ at $37^{\circ} \mathrm{C}$ to the determine the MBC.

internalize spherical silver nanoparticles, and that most of the internalized silver nanoparticles are present in the endolysosomal cell compartment of hMSC. ${ }^{25,88,89}$ Compared to the observed shape-dependent antibacterial effect, there was no difference in the cytotoxic effect towards hMSC. 
Table 3 MBC of silver nanoparticles with different particle shapes (given in $\mu \mathrm{g} \mathrm{mL}^{-1}$ of silver). The antimicrobial effect of silver nanoparticles decreased when higher numbers of $S$. aureus were used for inoculation. Furthermore, the toxicity towards bacteria corresponds to the dissolution kinetics of the nanoparticles: platelets $>$ spheres glucose synthesis $>$ spheres microwave synthesis $\approx$ rods $>$ cubes

\begin{tabular}{lllll}
\hline S. aureus $(N)$ & $1 \times 10^{5}$ & $1 \times 10^{4}$ & $1 \times 10^{3}$ & $1 \times 10^{2}$ \\
Spheres glucose synthesis & $>50$ & $\geq 50$ & $\geq 25$ & $\geq 12.5-25$ \\
Spheres microwave & $>50$ & $\geq 50$ & $\geq 25$ & $\geq 25$ \\
synthesis & & & & \\
Platelets & $\geq 50$ & $\geq 25$ & $\geq 25$ & $\geq 25$ \\
Cubes & $>50$ & $>50$ & $\geq 50$ & $\geq 25-50$ \\
Rods & $>50$ & $\geq 50$ & $\geq 25$ & $\geq 25$
\end{tabular}

\section{Conclusions}

In the presence of oxygen, silver nanoparticles of all shapes dissolve in pure water. The dissolution kinetics were correlated to the estimated specific surface area of the particles, where particles with a higher specific surface area dissolve faster than particles with a smaller one. By confocal laser scanning microscopy, it was shown that all particles were taken up by endocytosis of human mesenchymal stem cells. It can be assumed that they start to dissolve in the endolysosomes. This particle uptake was not shape-dependent, probably due to the short uptake time (several hours) where the dissolution rate is similar for all kinds of silver nanoparticles. A toxic effect to these cells was observed at concentrations $>12.5 \mu \mathrm{g} \mathrm{mL}{ }^{-1}$, but no shape dependence was found. Contrary to that, the toxicity towards bacteria corresponded very well to the dissolution kinetics and therefore to the particle morphology. Particles with a higher specific surface area were more toxic for bacteria than particles with smaller specific surface areas. This suggests that $\mathrm{Ag}^{+}$is the predominant toxic species towards bacteria. The difference in the dissolution rate may be exploited to apply silver nanoparticles with a relatively higher bacterial effect with a lower cytotoxic effect towards tissue.

\section{Acknowledgements}

We thank the Deutsche Forschungsgemeinschaft (DFG) for funding in the framework of the priority program 1313. We thank Dr Joerg Diendorf for experimental assistance with the dissolution of the silver bar.

\section{Notes and references}

1 G. Schmid, Nanoparticles. From Theory to Application, WileyVCH, Weinheim, 2004.

2 X. Y. Dong, Z. W. Gao, K. F. Yang, W. Q. Zhang and L. W. Xu, Catal. Sci. Technol., 2015, 5, 2554-2574.

3 Y. Gao, P. Jiang, L. Song, L. Liu, X. Yan, Z. Zhou, D. Liu, J. Wang, H. Yuan, Z. Zhang, X. Zhao, X. Dou, W. Zhou, G. Wang and S. Xie, J. Phys. D: Appl. Phys., 2005, 38, 10611067.
4 H. Choi, S. J. Ko, Y. Choi, P. Joo, T. Kim, B. R. Lee, J. W. Jung, H. J. Choi, M. Cha, J. R. Jeong, I. W. Hwang, M. H. Song, B. S. Kim and J. Y. Kim, Nat. Photonics, 2013, 7, 732-738.

5 M. S. Hu, H. L. Chen, C. H. Shen, L. S. Hong, B. R. Huang, K. H. Chen and L. C. Chen, Nat. Mater., 2006, 5, 102-106.

6 M. Kauranen and A. V. Zayats, Nat. Photonics, 2012, 6, 737748.

7 X. Chen and H. J. Schluesener, Toxicol. Lett., 2008, 176, 1-12. 8 P. D. Howes, R. Chandrawati and M. M. Stevens, Science, 2014, 346, 1247390.

9 S. Linic, P. Christopher and D. B. Ingram, Nat. Mater., 2011, 10, 911-921.

10 S. Chernousova and M. Epple, Angew. Chem., Int. Ed., 2013, 52, 1636-1653.

11 B. Nowack, H. F. Krug and M. Height, Environ. Sci. Technol., 2011, 45, 1177-1183.

12 W. K. Jung, H. C. Koo, K. W. Kim, S. Shin, S. H. Kim and Y. H. Park, Appl. Environ. Microbiol., 2008, 74, 2171-2178.

13 K. Markowska, A. M. Grudniak and K. I. Wolska, Acta Biochim. Pol., 2013, 60, 523-530.

14 W. Zimmerli, J. Intern. Med., 2014, 276, 111-119.

15 M. Beattie and J. Taylor, J Clin. Nurs., 2011, 20, 2098-2108.

16 D. M. Eby, H. R. Luckarift and G. R. Johnson, ACS Appl. Mater. Interfaces, 2009, 1, 1553-1560.

17 F. Furno, K. S. Morley, B. Wong, B. L. Sharp, P. L. Arnold, S. M. Howdle, R. Bayston, P. D. Brown, P. D. Winship and H. J. Reid, J. Antimicrob. Chemother., 2004, 54, 1019-1024.

18 M. L. W. Knetsch and L. H. Koole, Polymers, 2011, 3, 340366.

19 D. R. Monteiro, L. F. Gorup, A. S. Takamiya, A. C. RuvolloFilho, E. R. Camargo and D. B. Barbosa, Int. J. Antimicrob. Agents, 2009, 34, 103-110.

20 K. N. J. Stevens, S. Croes, R. S. Boersma, E. E. Stobberingh, C. van der Marel, F. H. van der Veen, M. L. W. Knetsch and L. H. Koole, Biomaterials, 2011, 32, 1264-1269.

21 K. Vasilev, V. Sah, K. Anselme, C. Ndi, M. Mateescu, B. Dollmann, P. Martinek, H. Ys, L. Ploux and H. J. Griesser, Nano Lett., 2009, 10, 202-207.

22 C. Greulich, S. Kittler, M. Epple, G. Muhr and M. Köller, Langenbecks Arch. Surg., 2009, 394, 495-502.

23 C. Greulich, J. Diendorf, J. Geßmann, T. Simon, T. Habijan, G. Eggeler, T. A. Schildhauer, M. Epple and M. Köller, Acta Biomater., 2011, 7, 3505-3514.

24 C. Sengstock, J. Diendorf, M. Epple, T. A. Schildhauer and M. Köller, Beilstein J. Nanotechnol., 2014, 5, 2058-2069.

25 C. Greulich, J. Diendorf, T. Simon, G. Eggeler, M. Epple and M. Köller, Acta Biomater., 2011, 7, 347-354.

26 C. Greulich, D. Braun, A. Peetsch, J. Diendorf, B. Siebers, M. Epple and M. Koller, RSC Adv., 2012, 2, 6981-6987.

27 S. Kittler, C. Greulich, J. Diendorf, M. Köller and M. Epple, Chem. Mater., 2010, 22, 4548-4554.

28 J. Liu, D. A. Sonshine, S. Shervani and R. H. Hurt, ACS Nano, 2010, 4, 6903-6913.

29 L. Liu and R. H. Hurt, Environ. Sci. Technol., 2010, 44, 21692175. 
30 K. Loza, J. Diendorf, C. Greulich, L. Ruiz-Gonzales, J. M. Gonzalez-Calbet, M. Vallet-Regi, M. Koeller and M. Epple, J. Mater. Chem. B, 2014, 2, 1634-1643.

31 Y. Xia, X. Xia and H. C. Peng, J. Am. Chem. Soc., 2015, 137, 7947-7966.

32 Y. Xia, X. Xia, Y. Wang and S. Xie, MRS Bull., 2013, 38, 335344.

33 Y. N. Xia, Y. Xiong, B. Lim and S. E. Skrabalak, Angew. Chem., Int. Ed., 2009, 48, 60-103.

34 S. H. Im, Y. T. Lee, B. Wiley and Y. Xia, Angew. Chem., Int. Ed., 2005, 44, 2154-2157.

35 H. Mehenni, L. Sinatra, R. Mahfouz, K. Katsiev and O. M. Bakr, RSC Adv., 2013, 3, 22397-22403.

36 E. V. Panfilova, B. N. Khlebtsov, A. M. Burov and N. G. Khlebtsov, Colloid J., 2012, 74, 99-109.

37 M. Rycenga, J. M. McLellan and Y. Xia, Adv. Mater., 2008, 20, 2416-2420.

38 A. R. Siekkinen, J. M. McLellan, J. Chen and Y. Xia, Chem. Phys. Lett., 2006, 432, 491-496.

39 S. E. Skrabalak, L. Au, X. D. Li and Y. N. Xia, Nat. Protoc., 2007, 2, 2182-2190.

40 Y. G. Sun and Y. N. Xia, Science, 2002, 298, 2176-2179.

41 Y. Wang, Y. Q. Zheng, C. Z. Huang and Y. N. Xia, J. Am. Chem. Soc., 2013, 135, 1941-1951.

42 D. Yu and V. W. W. Yam, J. Am. Chem. Soc., 2004, 126, 1320013201.

43 D. B. Yu and V. W. W. Yam, J. Phys. Chem. B, 2005, 109, 54975503.

44 Q. Zhang, W. Li, C. Moran, J. Zeng, J. Chen, L. Wen and Y. N. Xia, J. Am. Chem. Soc., 2010, 132, 11372-11378.

45 T. Miclaus, V. E. Bochenkov, R. Ogaki, K. A. Howard and D. S. Sutherland, Nano Lett., 2014, 14, 2086-2093.

46 S. Chen, Z. Fan and D. L. Carroll, J. Phys. Chem. B, 2002, 106, 10777-10781.

47 E. Hao, K. L. Kelly, J. T. Hupp and G. C. Schatz, J. Am. Chem. Soc., 2002, 124, 15182-15183.

48 Y. J. Xiong, A. R. Siekkinen, J. G. Wang, Y. D. Yin, M. J. Kim and Y. N. Xia, J. Mater. Chem., 2007, 17, 2600-2602.

49 T. Darmanin, P. Nativo, D. Gilliland, G. Ceccone, C. Pascual, B. De Berardis, F. Guittard and F. Rossi, Colloids Surf., A, 2012, 395, 145-151.

50 A. Knauer and J. M. Köhler, Chem. Ing. Tech., 2013, 85, 467475.

51 Y. Sun, B. Mayers, T. Herricks and Y. Xia, Nano Lett., 2003, 3, 955-960.

52 W. M. Schuette and W. E. Buhro, ACS Nano, 2013, 7, 38443853.

53 A. A. Zinchenko, K. Yoshikawa and D. Baigl, Adv. Mater., 2005, 17, 2820-2823.

54 B. J. Wiley, Y. Xiong, Z. Y. Li, Y. Yadong Yin and Y. Xia, Nano Lett., 2006, 6, 765-768.

55 O. Harush-Frenkel, N. Debotton, S. Benita and Y. Altschuler, Biochem. Biophys. Res. Commun., 2007, 353, 26-32.

56 K. Cha, H. W. Hong, Y. G. Choi, M. J. Lee, J. H. Park, H. K. Chae, G. Ryu and H. Myung, Biotechnol. Lett., 2008, 30, 1893-1899.
57 Y. C. Chung, I. H. Chen and C. J. Chen, Biomaterials, 2008, 29, 1807-1816.

58 L. Kastl, D. Sasse, V. Wulf, R. Hartmann, J. Mircheski, C. Ranke, S. Carregal-Romero, J. A. Martínez-López, R. Fernández-Chacón, W. J. Parak, H. P. Elsasser and P. Rivera-Gil, ACS Nano, 2013, 7, 6605-6618.

59 L. Shang, K. Nienhaus, X. Jiang, L. Yang, K. Landfester, V. Mailänder, T. Simmet and G. U. Nienhaus, Beilstein J. Nanotechnol., 2014, 5, 2388-2397.

60 D. A. Kuhn, D. Vanhecke, B. Michen, F. Blank, P. Gehr, A. Petri-Fink and B. Rothen-Rutishauser, Beilstein J. Nanotechnol., 2014, 5, 1625-1636.

61 G. A. Sotiriou and S. E. Pratsinis, Curr. Opin. Chem. Eng., 2011, 1, 3-10.

62 G. A. Martinez-Castanon, N. Nino-Martinez, F. MartinezGutierrez, J. R. Martinez-Mendoza and F. Ruiz, J. Nanopart. Res., 2008, 10, 1343-1348.

63 X. Hong, J. Wen, X. Xiong and Y. Hu, Environ. Sci. Pollut. Res., 2015, 1-9, DOI: 10.1007/s11356-015-5668-z.

64 L. Actis, A. Srinivasan, J. L. Lopez-Ribot, A. K. Ramasubramanian and J. L. Ong, J. Mater. Sci.: Mater. Med., 2015, 26, 1-7.

65 P. M. Favi, M. M. Valencia, P. R. Elliott, A. Restrepo, M. Gao, H. Huang, J. J. Pavon and T. J. Webster, J. Biomed. Mater. Res., Part A, 2015, 103, 3940-3955.

66 S. Pal, Y. K. Tak and J. M. Song, Appl. Environ. Microbiol., 2007, 73, 1712-1720.

67 S. Ahlberg, A. Antonopulos, J. Diendorf, R. Dringen, M. Epple, R. Flöck, W. Goedecke, C. Graf, N. Haberl, J. Helmlinger, F. Herzog, F. Heuer, S. Hirn, C. Johannes, S. Kittler, M. Köller, K. Korn, W. G. Kreyling, F. Krombach, J. Lademann, K. Loza, E. M. Luther, M. Malissek, M. C. Meinke, D. Nordmeyer, A. Pailliart, J. Raabe, F. Rancan, B. Rothen-Rutishauser, E. Rühl, C. Schleh, A. Seibel, C. Sengstock, L. Treuel, A. Vogt, K. Weber and R. Zellner, Beilstein J. Nanotechnol., 2014, 5, 1944-1965.

68 J. Zeng, Y. Zheng, M. Rycenga, J. Tao, Z. Y. Li, Q. Zhang, Y. Zhu and Y. N. Xia, J. Am. Chem. Soc., 2010, 132, 8552-8553. 69 B. Wiley, Y. Sun and Y. Xia, Langmuir, 2005, 21, 8077-8080. 70 H. S. Wang, X. L. Qiao, J. G. Chen and S. Y. Ding, Colloids Surf., A, 2005, 256, 111-115.

71 J. Helmlinger, M. Heise, M. Heggen, M. Ruck and M. Epple, RSC Adv., 2015, 5, 92144-92150.

72 S. Banerjee, K. Loza, W. Meyer-Zaika, O. Prymak and M. Epple, Chem. Mater., 2014, 26, 951-957.

73 C. Batchelor-McAuley, K. Tschulik, C. C. M. Neumann, E. Laborda and R. G. Compton, Int. J. Electrochem. Sci., 2014, 9, 1132-1138.

74 R. D. Kent and P. J. Vikesland, Environ. Sci. Technol., 2012, 46, 6977-6984.

75 J. M. Zook, S. E. Long, D. Cleveland, C. L. A. Geronimo and R. I. MacCuspie, Anal. Bioanal. Chem., 2011, 401, 1993-2002.

76 C. Levard, B. C. Reinsch, F. M. Michel, C. Oumahi, G. V. Lowry and G. E. Brown, Environ. Sci. Technol., 2011, 45, 5260-5266.

77 C. M. Ho, C. K. Wong, S. K. W. Yau, C. N. Lok and C. M. Che, Chem.-Asian J., 2011, 6, 2506-2511. 
78 X. Li, J. J. Lenhart and H. W. Walker, Langmuir, 2010, 26, 16690-16698.

79 S. Kittler, C. Greulich, J. S. Gebauer, J. Diendorf, L. Treuel, L. Ruiz, J. M. Gonzalez-Calbet, M. Vallet-Regi, R. Zellner, M. Köller and M. Epple, J. Mater. Chem., 2010, 20, 512-518. 80 B. Stringer, A. Imrich and L. Kobzik, Cytometry, 1995, 20, 2332.

81 H. Suzuki, T. Toyooka and Y. Ibuki, Environ. Sci. Technol., 2007, 41, 3018-3024.

82 I. Brook, Clin. Infect. Dis., 1989, 11, 361-368.

83 K. I. Udekwu, N. Parrish, P. Ankomah, F. Baquero and B. R. Levin, J. Antimicrob. Chemother., 2009, 63, 745-757.

84 S. Wang, R. Lawson, P. C. Ray and H. Yu, Toxicol. Ind. Health, 2011, 27, 547-554.
85 K. S. Butler, D. J. Peeler, B. J. Casey, B. J. Dair and R. K. Elespuru, Mutagenesis, 2015, 30, 577-591.

86 A. Kumar, A. K. Pandey, S. S. Singh, R. Shanker and A. Dhawan, Cytometry, Part A, 2011, 79, 707-712.

87 K. S. Butler, B. J. Casey, G. V. Garborcauskas, B. J. Dair and R. K. Elespuru, Mutat. Res., Genet. Toxicol. Environ. Mutagen., 2014, 768, 14-22.

88 Y. Hu, K. Cai, Z. Luo, R. Zhang, L. Yang, L. Deng and K. D. Jandt, Biomaterials, 2009, 30, 3626-3635.

89 H. Y. Nam, S. M. Kwon, H. Chung, S. Y. Lee, S. H. Kwon, H. Jeon, Y. Kim, J. H. Park, J. Kim, S. Her, Y. K. Oh, I. C. Kwon, K. Kim and S. Y. Jeong, J. Controlled Release, 2009, 135, 259-267. 